\title{
Efeitos de biorremediador sobre o processo de biodigestão anaeróbia de dejetos bovinos
}

O dejeto de bovino leiteiro é amplamente empregado na digestão anaeróbia, no entanto, apresenta características que requerem mediação para alcançar melho desempenho. Assim, objetivou-se avaliar a aplicação de doses crescentes e uma superdose de biorremediador na digestão anaeróbia de dejetos de bovinos leiteiros. Foi utilizado o delineamento inteiramente casualizado, com quatro tratamentos, correspondentes as quatros doses de biorremediador testadas ( 0 ; 0,5 1,0 e $10 \mathrm{~mL}$ ), conduzidos em temperatura ambiente, em biodigestores de bancada de volume útil de 1,8 L. Os resultados foram submetidos a regressão polinomial, sendo selecionados os modelos significativos. Os resultados apresentaram que a aplicação de biorremediador ao dejeto bovino leiteiro interferiu o desempenho do processo, sendo que a dose testada de $1,0 \mathrm{~mL}$ até a dose estimada de $5 \mathrm{~mL}$ de biorremediador melhorou os potenciais de produção de biogás e metano e as reduções de sólidos.

Palavras-chave: Biogás; Energia renovável; Enzimas; Tratamento de dejetos.

\section{Effects of bioremediation on the anaerobic biodigestion process of cattle manure}

Dairy cattle manure is widely used in anaerobic digestion, however, it has characteristics that require mediation to achieve better performance. Thus, the objective was to evaluate the application of increasing doses and an overdose of bioremediator in the anaerobic digestion of manure from dairy cattle. A completely randomized design was used, with four treatments, corresponding to the four tested bioremediation doses $(0 ; 0.5 ; 1.0$ and $10 \mathrm{~mL})$, carried out at room temperature, in bench-top digesters with a useful volume of $1.8 \mathrm{~L}$ The results were submitted to polynomial regression, and significant models were selected. The results showed that the application of bioremediation to bovine dairy manure interfered with the performance of the process, and the tested dose of $1.0 \mathrm{~mL}$ up to the estimated dose of $5 \mathrm{~mL}$ of bioremediation improved the potentials of biogas and methane production and the reductions in solids.

Keywords: Biogas; Renewable energy; Enzymes; Waste treatment.

Topic: Desenvolvimento, Sustentabilidade e Meio Ambiente

Reviewed anonymously in the process of blind peer.
Received: 06/06/2021

Approved: 28/06/2021
Aline Fernandes

Universidade Estadual Paulista Júlio de Mesquita Filho, Brasil http://lattes.cnpq.br/4376159254407665

aline.nands@hotmail.com

Paula Maria Pilotto Branco (iD)

Centro Universitário de Jaguariúna, Brasil

http://lattes.cnpq.br/5765907668405091

http://orcid.org/0000-0001-8297-9352

paulapilotto@hotmail.com

Luana Alves Akamine (iD

Universidade Estadual Paulista Júlio de Mesquita Filho, Brasil

http://lattes.cnpq.br/2780341257922558

http://orcid.org/0000-0002-4567-2818

luana.a.akamine@gmail.com

\author{
João Antônio Silva Sousa (in \\ Universidade Estadual Paulista Júlio de Mesquita Filho, Brasil \\ http://lattes.cnpq.br/1781943305374696 \\ http://orcid.org/0000-0001-8349-7443 \\ joaoantonio.biologo@hotmail.com \\ Jorge de Lucas Júnior (iD \\ Universidade Estadual Paulista Júlio de Mesquita Filho, Brasil \\ http://lattes.cnpq.br/3868629166600922 \\ http://orcid.org/0000-0002-5515-3931 \\ jorge.lucas-junior@unesp.br
}

Referencing this:

FERNANDES, A.; BRANCO, P. M. P.; AKAMINE, L. A.; SOUSA, J. A. S.; LUCAS JUNIOR, J.. Efeitos de biorremediador sobre o processo de biodigestão anaeróbia de dejetos bovinos. Revista Ibero Americana de Ciências Ambientais, v.12, n.6, p.472-482, 2021. DOI: http://doi.org/10.6008/CBPC2179-6858.2021.006.0039 


\section{INTRODUÇÃO}

O controle ambiental é pauta de reuniões governamentais e de centros de pesquisas que buscam tecnologias para solucionar os efeitos negativos resultantes do desenvolvimento e do intenso crescimento populacional sobre o ambiente e à saúde pública (SILVEIRA FILHO et al., 2018).

Ponto que a energia proveniente da biomassa é contribuinte devido a quantidade de resíduos gerados nos setores agropecuário, agroindustrial e urbano, sendo capaz de agregar valor econômico nas diversas cadeias do agronegócio, potencializar a participação da energia renovável na geração distribuída de eletricidade e promover a sustentabilidade ambiental (ALBUQUERQUE et al., 2016; FERREIRA et al., 2018).

Com relação ao complexo agroindustrial brasileiro, a cadeia produtiva do leite é uma das mais relevantes, com destaque na geração de emprego e renda (ROCHA et al., 2018). No entanto, pela decorrente concentração dos dejetos provenientes da atividade há intensificação dos impactos ambientais o que leva a busca por alternativas de mitigação e reaproveitamento dos resíduos gerados visando retorno econômico (KUNZ et al., 2006).

De tal modo, o dejeto de bovino leiteiro (DBL) é muito utilizado no processo de digestão anaeróbia (DA), porém por apresentar teor de sólidos totais com material fibroso de difícil degradação, faz com que o rendimento de produção de biogás seja inferior aos rendimentos de produções dos animais não ruminantes (ZULKIFLI et al., 2015; SUNADA et al., 2018).

Em meio a algumas pesquisas com objetivo de otimizar a DA sobressaem as técnicas de prétratamentos, divididos principalmente em: térmico, mecânico, químico, físico e biológico (MAGDALENA et al., 2018; ZHANG et al., 2018). Sendo o pré-tratamento biológico, como o uso de enzimas, visto como o ambientalmente correto por além de oferecer melhorias nas condições do substrato para fermentação requer baixa demanda por energia (RODRIGUEZ et al., 2017; CORDOVA et al., 2017; ROMANO et al., 2009). Outro método atrativo do uso de enzimas é sua aplicação direta ao biodigestor por não requerer equipamentos extras (BRÉMOND et al., 2018).

Estudos encontrados relacionados aos benefícios da adição de enzimas sobre o desempenho da DA apresentam resultados divergentes (GARCIA et al., 2019). Desse modo, as pesquisas atuais estão voltadas ao uso dessas técnicas de forma integrada, como na aplicação conjunta de um pré-tratamento mais a aplicação de aditivos (ZHANG et al., 2018).

Portanto, objetivou-se avaliar os efeitos de doses de um biorremediador sobre a viabilidade técnica na digestão anaeróbia de dejetos de bovinos leiteiros peneirados.

\section{MATERIAIS E MÉTODOS}

\section{Biodigestor e substrato}

O substrato utilizado para abastecer os biodigestores bateladas foi composto por água e dejetos de bovinos leiteiros, provenientes de vacas da raça Holandesa, em lactação. O dejeto foi coletado nas instalações de semiconfinamento, nas dependências do Setor de Bovinocultura do Departamento de 
Zootecnia, situado na UNESP-FCAV.

Após calculadas as quantidades de dejetos, considerando-se $4 \%$ de sólidos totais, e de água, com a função de diluição do dejeto, a mistura foi submetida a uma peneira de malha de $2 \mathrm{~mm}$, no qual retirou-se o material de maior diâmetro que ficou retido, e o material que passou pela peneira foi utilizado como substrato para os tratamentos utilizados.

O produto comercial utilizado nesta pesquisa, será chamado de biorremediador e foi cedido por uma empresa, localizada na região da cidade de Jaboticabal. Esse produto é composto por um complexo enzimático: amilase, celulase, pectinase, fitase, lipase e protease, e pôr os probióticos: Lactobacilos Acidófilos, Bifidobacterium Longum, Bifidobacterium Thermophilum e Bacillus Subtilis liofilizados em maltodextrina.

Os biodigestores utilizados foram confeccionados por tubos de PVC de $50 \mathrm{~cm}$ de comprimento com diâmetros de 75, 100 e 150mm, e CAP de PVC de diâmetro de 100 e 150mm. O biodigestor, com volume total de dois litros, foi disposto de maneira em que o tubo de $150 \mathrm{~mm}$ permanece fixado no CAP correspondente ao seu diâmetro, assumindo a base do biodigestor, no seu interior foi fixado o tubo de $75 \mathrm{~mm}$ o qual é destinado a câmera de fermentação do substrato. O espaço existente entre a parede externa do cilindro interior e a parede interna do cilindro exterior comporta um volume de água ("selo de água"). 0 tubo de diâmetro intermediário teve uma das extremidades vedadas por outro CAP, conservando-se apenas uma abertura com um registro para descargas do biogás e esse permanece inserido no selo de água, para propiciar condições anaeróbias e armazenar o biogás produzido.

Para o ensaio dos biodigestores bateladas, foram utilizadas 16 unidades, com capacidade para $2 \mathrm{~L}$, sendo 1,8 L de volume útil. Foram avaliados quatro tratamentos, com quatro repetições cada. $\mathrm{O}$ ensaio foi conduzido em temperatura ambiente sendo a média de $26,7^{\circ} \mathrm{C}$, a mínima de $21,9^{\circ} \mathrm{C}$ e a máxima de $33,4^{\circ} \mathrm{C}$ permanecendo durante todo o ensaio dentro da faixa mesofílica (20 a $45 \stackrel{\circ}{\circ}$ ), sendo uma das faixas propicias ao crescimento microbiológico anaeróbio (CHERNICHARO, 2007), até a produção de biogás cessar (123 dias).

O biorremediador foi testado nas doses de $0 ; 0,5 ; 1,0$ e $10 \mathrm{~mL}$, sendo a dose de 1,0 mL determinada com base em trabalho que obteve resultados eficientes com biorremediador na DA (COSTA, et al., 2013) e a concentração dez vezes maior, ou seja, uma superdose com a finalidade de ampliar o conhecimento do efeito do biorremediador (BINNER et al., 2012) sobre a DA dos dejetos bovino leiteiro. O substrato composto por DBL diluído em água recebeu a adição do produto comercial, no momento do abastecimento, variando-se as doses (Tabela 1).

Tabela 1: Composição dos substratos dos tratamentos.

\begin{tabular}{lll}
\hline Doses & Componentes & \\
\cline { 2 - 3 } Biorremediador $(\mathrm{mL})$ & Dejeto Bovino $(\mathrm{Kg})$ & Água $(\mathrm{Kg})$ \\
\hline 0 & 0,5 & 1,300 \\
0,5 & 0,5 & 1,300 \\
1,0 & 0,5 & 1,300 \\
10,0 & 0,5 & 1,300 \\
\hline
\end{tabular}

Teores de sólidos totais e sólidos voláteis 
Para determinação de sólidos totais, as amostras dos afluentes e efluentes foram acondicionadas em triplicata em recipientes de alumínio, previamente tarados e pesados para obtenção do peso úmido (Pu) do material em balança com precisão de 0,01g. Posteriormente, foram levados à estufa com circulação forçada de ar, a temperatura de 65으, até atingirem peso constante.

Após serem retirados da estufa, aguardou-se para atingirem temperatura ambiente e então, foram novamente pesadas, obtendo-se o peso seco (Ps). O teor de sólidos totais foi determinado semanalmente segundo metodologia descrita por APHA et al. (2005). O teor de sólidos totais (ST), em porcentagem, foi determinado por meio da seguinte equação:

$$
S T=\left[1-\left(\frac{P u-P S}{P u}\right)\right] x 100
$$

Em que:

ST é o teor de ST, em porcentagem; PU é o peso úmido da amostra, em g;

PS é o peso seco da amostra, em $\mathrm{g}$.

Para a determinação dos sólidos voláteis, o material seco em estufa, resultante da determinação dos sólidos totais, foi levado à mufla, em cadinhos de porcelana previamente tarados em balança analítica com precisão de 0,0001g, e mantidos a uma temperatura de 575 C por um período de 2 horas.

Após o resfriamento em dessecadores, o material resultante foi pesado, obtendo-se o peso da matéria mineral. Os teores de sólidos voláteis foram determinados semanalmente e expressos em porcentagem de matéria seca segundo metodologia descrita por APHA et al. (2005).

$$
S V=\left[1-\left(\frac{P f-T}{P i-T}\right)\right] x 100
$$

Em que:

SV é o teor de SV, em porcentagem;

Pi é o peso inicial da amostra, em g; Pf é o peso obtido após queima em mufla, em g;

Té a tara do cadinho, em $\mathrm{g}$.

As eficiências de remoção de ST e SV foram calculadas a partir das concentrações iniciais (antes da digestão anaeróbia) e finais (depois da digestão anaeróbia).

\section{Determinação do volume de biogás e cálculo dos potenciais de produção de biogás}

O volume de biogás produzido de cada biodigestor foi mensurado pela medida do deslocamento vertical dos gasômetros através de régua graduada, multiplicado o dado registrado pela área da seção transversal interna dos gasômetros. Após cada leitura, o registro de descarga de biogás era aberto até que os gasômetros fossem zerados e em seguida eram fechados.

A correção do volume de biogás para as condições de 1 atm e $20^{\circ} \mathrm{C}$ foi efetuada com base no trabalho de Caetano (1985), no qual verificou-se que, pelo fator de compressibilidade (Z), o biogás apresentou comportamento próximo ao ideal. Conforme descrito por Santos (2001), para a correção do volume de biogás, utilizou-se a expressão resultante da combinação das leis de Boyle e Gay-Lussac:

$$
\underline{\mathrm{VoPO}}=\underline{\mathrm{V} 1 \mathrm{~T} 1}
$$


To T1

(3)

Em que:

Vo é volume de biogás corrigido, $\mathrm{m}^{3}$; Po é a pressão corrigida do biogás, $10322,72 \mathrm{~mm}$ de água; To é a temperatura corrigida do biogás, 293,15 K; V1 é volume do gás no gasômetro; P1 é a pressão do biogás no instante da leitura, 9652,10 mm de água; T1 é a temperatura do biogás, em $\mathrm{K}$, no instante da leitura.

A produção de biogás e $\mathrm{CH}_{4}$ e as concentrações de ST e SV foram usadas para determinar os potenciais específicos de produção de biogás $\left(\mathrm{m}^{3} \mathrm{~kg}^{-1}\right)$ e de $\mathrm{CH} 4\left(\mathrm{~m}^{3} \mathrm{~kg}^{-1}\right)$.

\section{Mensuração de metano do biogás}

O teor de metano $\left(\mathrm{CH}_{4}\right)$ da composição do biogás foi determinado uma vez por semana. As amostras foram colhidas em seringas e injetadas no cromatógrafo de gás (modelo CG-2010 Plus, Shimadzu Scientific Instruments) equipado com um detector de ionização por plasma (BID-2010 Plus), utilizando hélio como gás de arraste em coluna Carboxen ${ }^{\circledR} 1010$ Plot.

\section{Análises estatísticas}

Os resultados foram analisados por meio de análise de regressão polinomial, sendo selecionados os modelos significativos e com maior coeficiente de determinação (R2).

\section{RESULTADOS E DISCUSSÃO}

Os valores médios de produção de biogás $\left(\mathrm{m}^{3} \mathrm{dia}^{-1}\right)$, produção de metano $\left(\mathrm{m}^{3} \mathrm{dia}^{-1}\right), \mathrm{CH}_{4}(\%)$, potenciais de produção de biogás e metano por $\mathrm{ST}_{\mathrm{adc}}$ e por $\mathrm{SV}_{\mathrm{adc}}$ estão descritos na Tabela 2.

Tabela 2: Desempenho técnico da produção e dos potenciais avaliados na DA de DBL em função das doses de biorremediador.

\begin{tabular}{|c|c|c|c|c|}
\hline \multirow{2}{*}{ Variáveis } & \multicolumn{4}{|c|}{ Biorremediador (mL) } \\
\hline & 0,0 & 0,5 & 1,0 & 10,0 \\
\hline PB $\left(m^{3} \mathrm{dia}^{-1}\right)$ & $0.0163 \pm 0,01$ & $0,0197 \pm 0,01$ & $0,0205 \pm 0,01$ & $0,0164 \pm 0,01$ \\
\hline $\mathrm{PM}\left(\mathrm{m}^{3} \mathrm{dia}^{-1}\right)$ & $0,0106 \pm 0,01$ & $0,0137 \pm 0,01$ & $0,0140 \pm 0,01$ & $0,0112 \pm 0,01$ \\
\hline $\mathrm{CH}_{4}(\%)$ & $64,79 \pm 1,88$ & $69,72 \pm 0,57$ & $68,30 \pm 1,94$ & $68,47 \pm 3,14$ \\
\hline PB (m³ Kg sTadc $\left.{ }^{-1}\right)$ & $0,2111 \pm 0,03$ & $0,2544 \pm 0,04$ & $0,2665 \pm 0,01$ & $0,1953 \pm 0,01$ \\
\hline PB (m³ Kg sVadc $\left.{ }^{-1}\right)$ & $0,2320 \pm 0,03$ & $0,2801 \pm 0,04$ & $0,2904 \pm 0,01$ & $0,2156 \pm 0,01$ \\
\hline PM $\left(\mathrm{m}^{3} \mathrm{Kg} \mathrm{sTadc}{ }^{-1}\right)$ & $0,0501 \pm 0,01$ & $0,0502 \pm 0,01$ & $0,0554 \pm 0,01$ & $0,0573 \pm 0,01$ \\
\hline PM $\left(\mathrm{m}^{3} \mathrm{Kg}\right.$ svadc $\left.^{-1}\right)$ & $0,0456 \pm 0,01$ & $0,0489 \pm 0,01$ & $0,0508 \pm 0,01$ & $0,0519 \pm 0,01$ \\
\hline
\end{tabular}

PB - Produção biogás; PM - Produção de metano.

As variáveis $\mathrm{PB}\left(\mathrm{m}^{3} \mathrm{dia}^{-1}\right), \mathrm{PM}\left(\mathrm{m}^{3} \mathrm{dia}^{-1}\right)$ e $\mathrm{CH}_{4}(\%)$ responderam de forma quadrática aos efeitos das doses do biorremediador (Figura 1A, 1B e 1C). A dose testada de 1,0 mL apresentou as melhores produções e teor de metano quando confrontado ao tratamento controle (sem a aplicação do biorremediador). Entretanto, a dose estimada de $5 \mathrm{~mL}$ apresentou ser a dose ótima, no qual a partir desse ponto as produções $\left(\mathrm{m}^{3} \mathrm{dia}^{-1}\right)$ e o teor de metano (\%) tendeu a decrescer com o aumento das doses do biorremediador. 

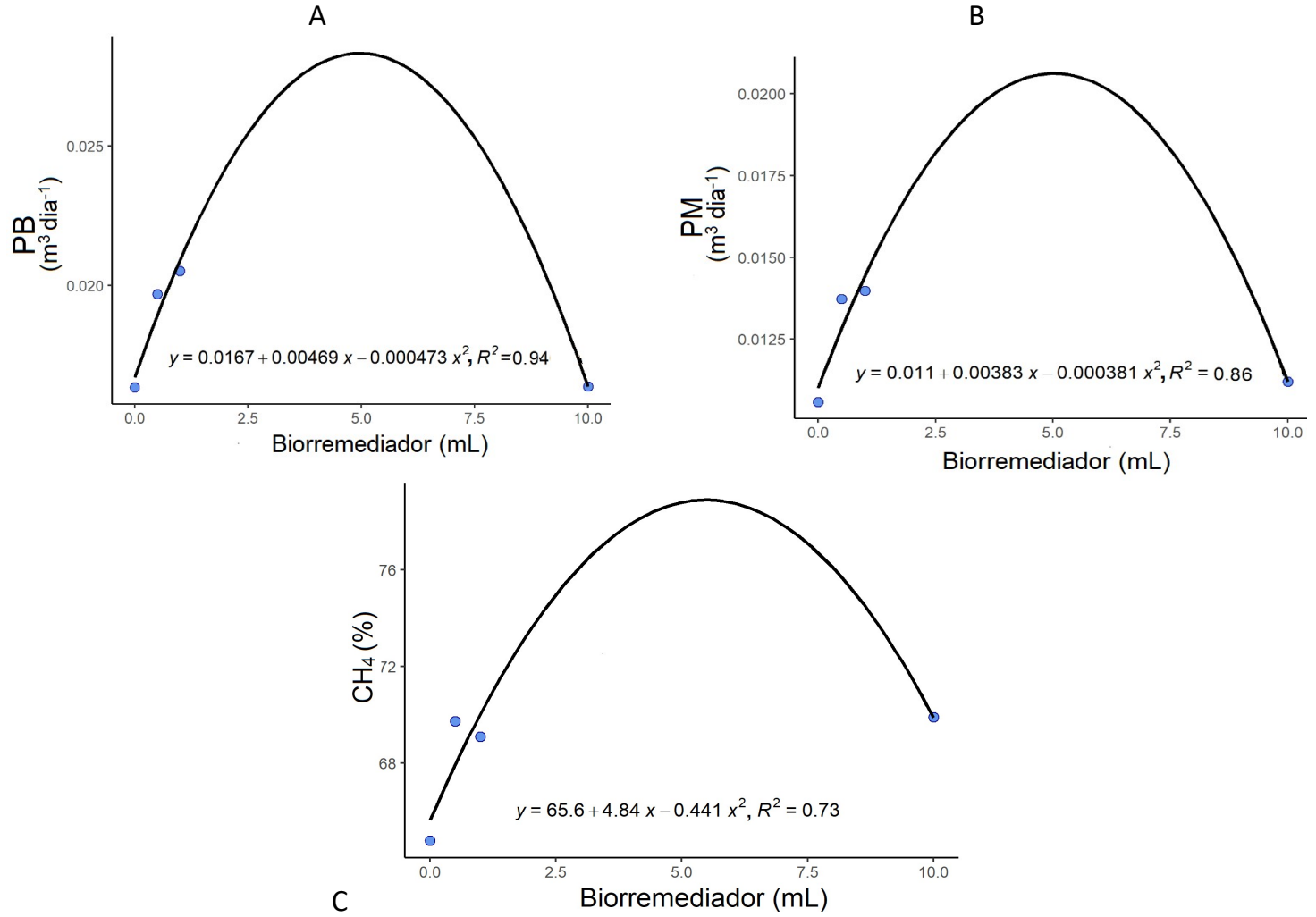

Figura 1: Produção biogás (A), produção de metano (B) e $\mathrm{CH}_{4}(\mathrm{C})$ da $\mathrm{DA}$ de $\mathrm{DBL}$ em função da aplicação direta de doses do biorremediador na carga de abastecimento.

Da mesma forma, a análise de regressão para os potenciais de produção de biogás e metano por $\mathrm{ST}_{\mathrm{adc}}$ e por $\mathrm{SV}_{\text {adc }}$ (Figura 2A, 2B, 2CE 2D) também indicou comportamento quadrático em que a dose testada de $1,0 \mathrm{~mL}$ proporcionou os melhores potenciais de produções, no entanto a dose estimada de $5 \mathrm{~mL}$ alcançou os potenciais de produções máximos. E a partir desse ponto essas variáveis começaram a terem seus rendimentos reduzidos o que pode estar relacionado as doses mais altas sofrerem a ação rápida e intensificada das enzimas constituintes do próprio biorremediador o que pode gerar desequilíbrio entre as fases do processo (BINNER et al., 2011). O comportamento quadrático dos potenciais é notado com clareza, com menor valor observado para dose testada de $10,0 \mathrm{~mL}$ do biorremediador o que aponta que o uso de altas doses é desfavorável ao processo, sendo os pontos de viabilidade técnica e a econômica a serem consideradas na seleção da dose a ser aplicada ao substrato (ZHANG et al., 2018).
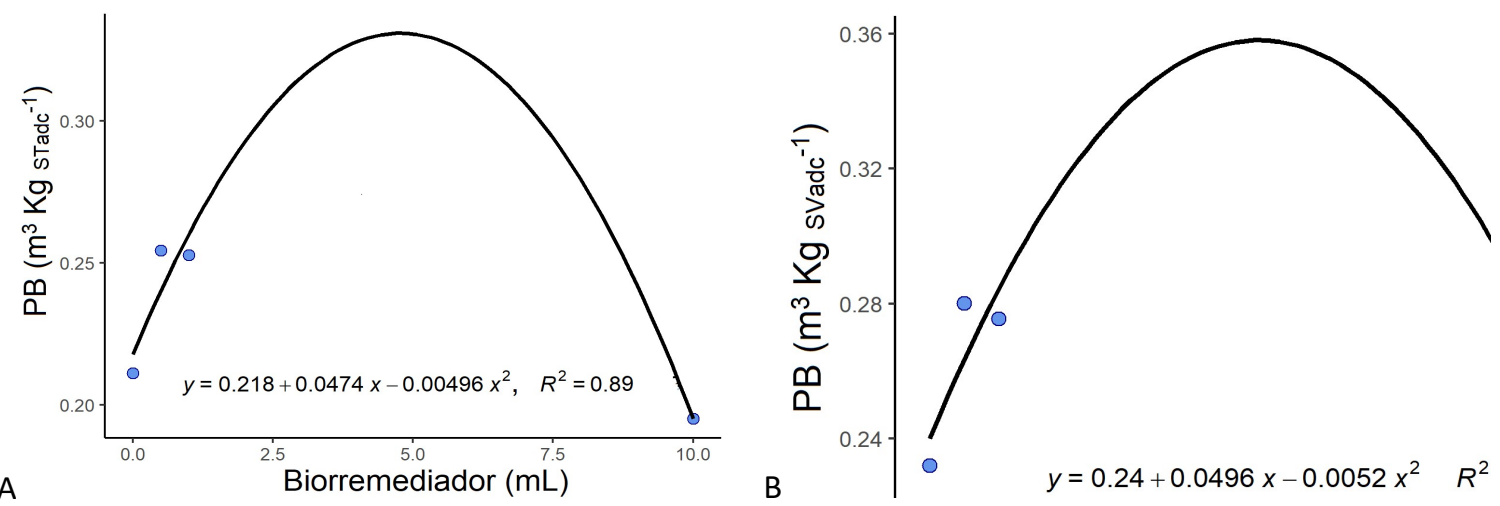

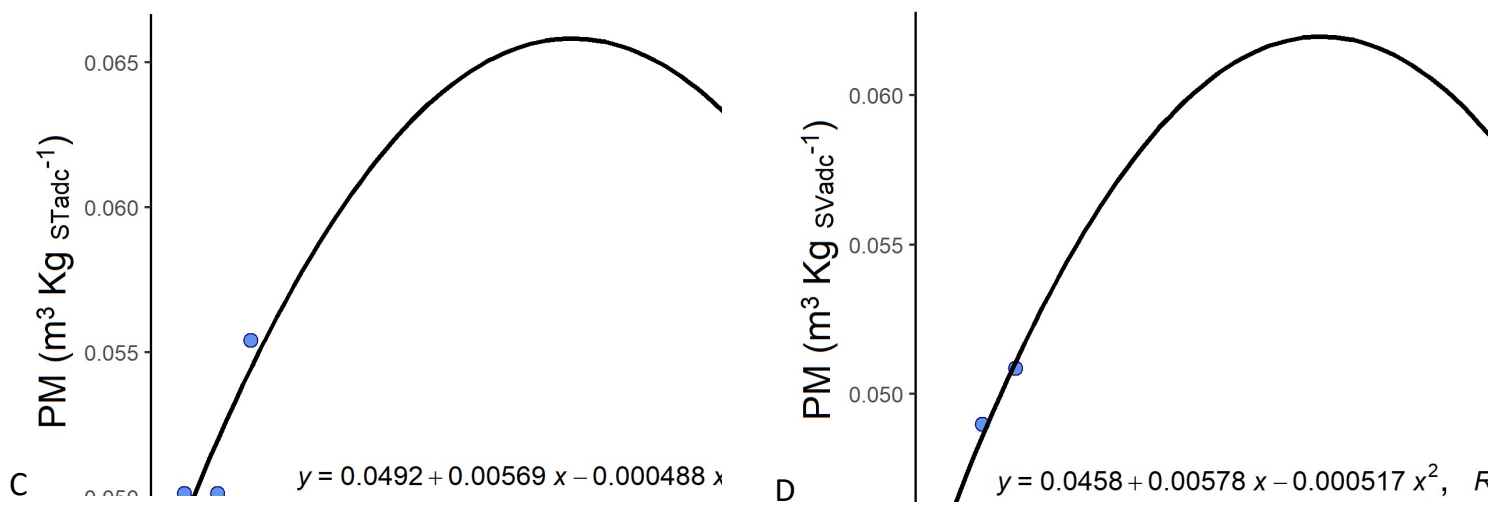

Figura 2: PB $\left(\mathrm{m}^{3} \mathrm{Kg} \mathrm{sTadc}^{-1}\right)$ (A), PB $\left(\mathrm{m}^{3} \mathrm{Kg} \mathrm{svadc}^{-1}\right)$ (B), PM $\left(\mathrm{m}^{3} \mathrm{Kg} \mathrm{sTadc}^{-1}\right)(C), \mathrm{PM}\left(\mathrm{m}^{3} \mathrm{Kg} \mathrm{svadc}^{-1}\right.$ (D) da DA de DBL em função da aplicação direta de doses do biorremediador na carga de abastecimento.

De modo geral, para as variáveis de produção de biogás e metano e seus potenciais específicos a melhor dose testada foi de $1,0 \mathrm{~mL}$ resultando produções superiores quando confrontadas com o tratamento controle, ou seja, o que não recebeu a aplicação de biorremediador.

Esse desempenho pode ser justificado pela composição da dieta oferecida aos bovinos leiteiros serem compostas por altos teores de lignina e celulose (MØLLER et al., 2004), as quais nem sempre são totalmente digeridas no trato digestório dos animais, assim constituindo cerca de $50 \%$ da matéria seca dos dejetos (CHEN et al., 2014), o que leva a necessidade de intervenção/REMEDIAÇÃO desse substrato para o aumento da hidrólise e melhor recuperação energética (GERHARDT et al., 2007).

Efeito que o biorremediador promoveu sobre a DA do DBL visto os melhores resultados com sua aplicação. Parawira et al. (2012) relatam que complexo enzimático proporciona condições desejáveis a ação das atividades catalíticas dos microrganismos. Indicando que as doses de 0,5 e 1,0 mL apresentaram a ação da atividade enzimática contida no biorremediador atuando na quebra dos polissacarídeos de degradação mais lenta (lignina e celulose), beneficiando a fase hidrolítica e como consequência as fases subsequentes da DA. Além do mais, possivelmente, o pré-tratamento mecânico (peneira) permitiu o melhor acesso dos microrganismos à parte mais complexa e passível à digestão (AHMAD et al., 2018; ROMANO et al., 2009).

Na Figura 3, é apresentada a produção de biogás nos primeiros 40 dias de fermentação, no qual pode se observar os picos de produções iniciais e após os comportamentos estáveis dos tratamentos durante o processo.

Quando se observa os 40 dias iniciais do processo anaeróbio, a dose de $10,0 \mathrm{~mL}$ apresentou o maior pico de produção logo na primeira semana, sendo que ao decorrer do processo sua produção foi reduzida e estabilizada (Figura 3) indicando que a degradação das enzimas adicionadas aos biodigestores ocorreu nos primeiros dias após o contato com a biomassa (GARCIA et al., 2019). Desempenho parecido ao encontrado no estudo realizado por Binner et al. (2011) que também não encontraram resultados significativos com a aplicação de uma superdosagem de enzimas na DA de silagem de milho, que explicam esse efeito pela decomposição rápida das enzimas adicionadas não serem capaz de contribuir significativamente com a degradação dos compostos complexos do substrato ao longo do processo.

Ainda pode-se observar na Figura 3 que o tratamento controle (sem aplicação do biorremediador) apresentou o menor pico de produção de biogás em comparação aos demais tratamentos, evidenciado que 
a aplicação de enzimas associada a outros pré-tratamentos melhora o efeito almejado (SPEDA et al., 2017).

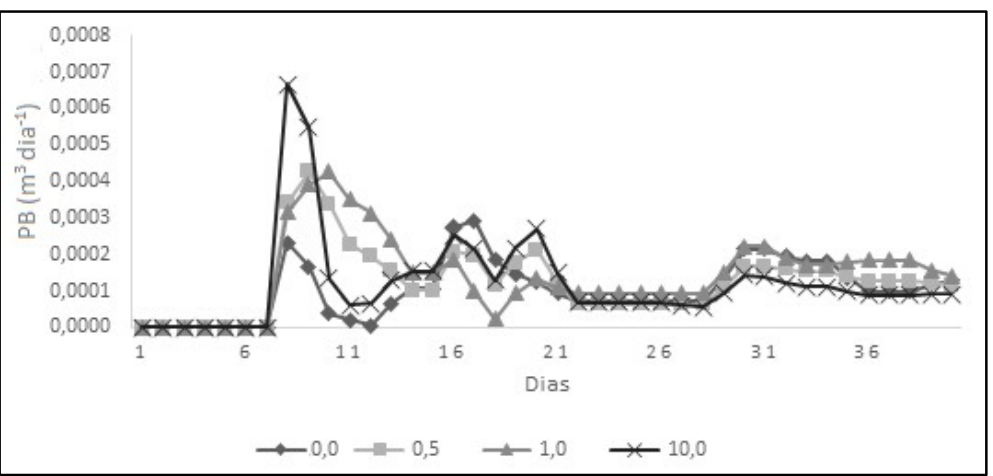

Figura 3: Produção diária de biogás $\left(\mathrm{m}^{3}\right)$ em função das doses de biorremediador com aplicação direta na carga de abastecimento.

O comportamento quadrático apresentado pela produção de biogás e metano $\left(\mathrm{m}^{3} \mathrm{dia}^{-1}\right)$ mostrou que mesmo quando a técnica visa melhor rendimento se for aplicada de forma excessiva pode causar efeito antagônico, como o acúmulo de ácidos graxos voláteis (AGV) e sua subsequente inibição devido à sobrecarga a fase da hidrólise (POLO et al., 2018).

A DA, naturalmente, gera vários tipos de AGV quem têm efeitos diferentes e cooperativos entre os grupos das bactérias anaeróbias (FRANKE-WHITTLE et al., 2014). No entanto, se as taxas de formação desses ácidos forem mais rápidas que a atividade das bactérias metanogênicas, ocorre condições não favoráveis às bactérias (JAIN et al., 2015) o que pode ter ocorrido logo após o pico de produção do tratamento com as doses estimadas superiores a $5 \mathrm{~mL}$ e a dose testada de $10,0 \mathrm{~mL}$ de biorremediador.

Entretanto, o dejeto bovino, dentre suas características, apresenta efeito sinérgico e possui altos teores de nutrientes essenciais para a atividade microbiológica o que o torna capaz de manter o pH estável (KAUFMANN, 2015; LIMA et al., 2016; NESHAT et al., 2017) o que pode ter proporcionado equilíbrio ao tratamento com a dose de $10,0 \mathrm{~mL}$ conforme observado pelo valor de $\mathrm{pH}$ final $(6,61)$ e pelo fato que mesmo apresentando desempenho de produção não proporcional ao seu pico inicial manteve-se estável durante o período avaliado (Figura 3).

Na Tabela 3 estão apresentados os valores médios das reduções de sólidos totais (\%) e voláteis (\%) resultantes da fermentação.

Tabela 3: Valores médios das reduções de sólidos totais (\%) e voláteis (\%) resultantes da fermentação.

\begin{tabular}{|c|c|c|c|c|}
\hline \multirow{2}{*}{ Variáveis } & \multicolumn{4}{|c|}{ Biorremediador $(\mathrm{mL})$} \\
\hline & 0,0 & 0,5 & 1,0 & 10,0 \\
\hline $\mathrm{ST}_{\text {red }}(\%)$ & $42,25 \pm 5,79$ & $37,2 \pm 1,67$ & $42,29 \pm 4,77$ & $52,85 \pm 11,16$ \\
\hline $\mathrm{SV}_{\text {red }}(\%)$ & $46,80 \pm 5,27$ & $41,64 \pm 1,73$ & $47,29 \pm 4,76$ & $56,16 \pm 11,04$ \\
\hline
\end{tabular}

STred - Sólidos totais reduzidos; $\mathrm{SV}_{\text {red }}$ - Sólidos voláteis reduzidos

O modelo quadrático não foi significativo em função das doses do biorremediador para $\mathrm{ST}_{\text {red }}(4 \mathrm{~A}) \mathrm{e}$ $\mathrm{SV}_{\text {red }}(4 \mathrm{~B})$. Para essas variáveis quanto maior a dose aplicada de biorremediador maior foram as reduções, demonstrando um comportamento linear e não quadrático.

A aplicação crescente do biorremediador causou diminuição na produção de biogás e metano $\left(\mathrm{m}^{3}\right.$ $\left.\mathrm{dia}^{-1}\right)$ e potenciais de biogás e metano $\left(\mathrm{m}^{3} \mathrm{Kg}_{\text {stadc }}{ }^{-1} \mathrm{e} \mathrm{m}^{3} \mathrm{Kg} \mathrm{svadc}^{-1}\right)$, mas efeito contrário apresentou nas 
reduções de sólidos (\%). Pode-se inferir que essas reduções de sólidos ocorreram, principalmente, nos primeiros dias do processo devido a ação do biorremediador, pois foi quando os tratamentos com as doses de 1,0 e 10,0 mL apresentaram os maiores picos de produção de biogás $\left(\mathrm{m}^{3} \mathrm{dia}^{-1}\right)$ (Figura 3).

A
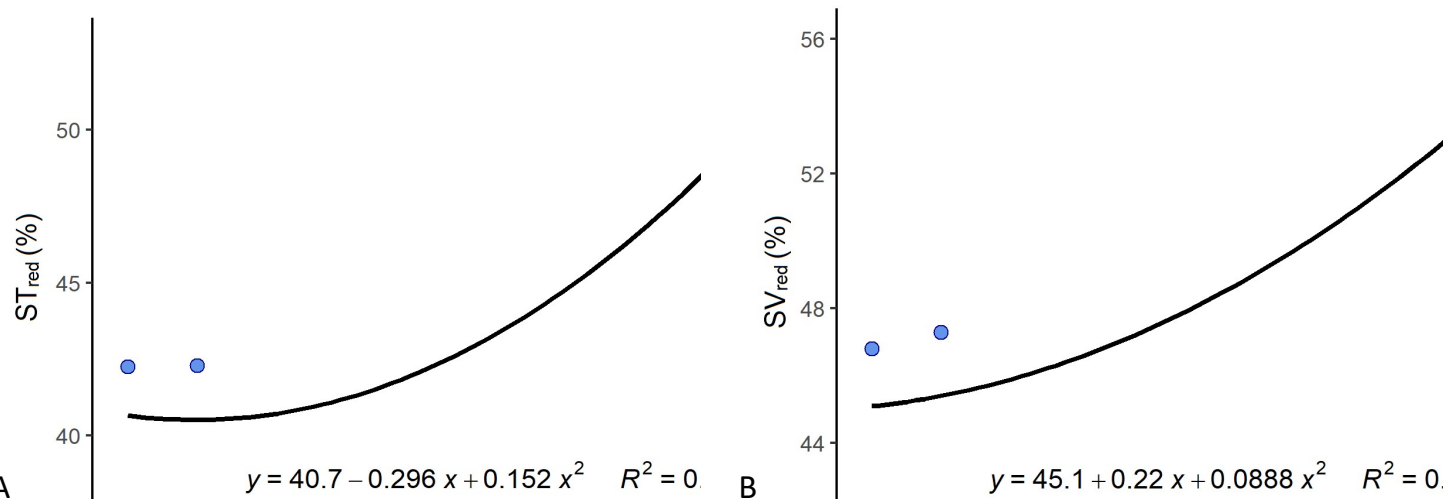

Figura 4: STred (A) e SVred (B) da DA de DBL em função da aplicação direta de doses do biorremediador na carga de abastecimento.

A dose de 1,0 mL do biorremediador demonstrou relação entre a remoção de SV (\%) (Tabela 4) e a produção de biogás $\left(\mathrm{m}^{3} \mathrm{dia}^{-1}\right.$ ) (Figura 9). Fato relacionado a produção de biogás ser proporcional a degradação do substrato, por dentre as frações constituintes dos sólidos totais a determinada como sólidos voláteis ser a fração convertida em biogás (JAIN et al., 2015; MERLINCHRISTY et al., 2014).

No entanto, comportamento oposto foi apresentado pela dose de $10,0 \mathrm{~mL}$ do biorremediador que não apresentou produção de biogás proporcional as reduções significativas de SV, provavelmente, porque nem toda a fração reduzida no processo foi convertido em biogás devido algum desequilíbrio entre as fases o que resulta a sua acumulação no interior dos biodigestores (IMENI et al., 2019).

\section{CONCLUSÕES}

$\mathrm{O}$ uso das doses testadas de 0,5 e 1,0 $\mathrm{mL}$ do biorremediador promoveram o melhor desempenho na DA dos dejetos de bovinos leiteiros, o que também demonstra que mesmo o dejeto bovino submetido a peneira no qual as menores frações de fibras não retidas ao terem a ação do biorremediador resultam melhor conversão em biogás. A dose de $10 \mathrm{~mL}$ apresentou maior pico inicial de produção (hidrólise mais intensa) e, em seguida, uma queda e estabilidade entre os demais tratamentos, sendo um indicativo de que doses altas do biorremediador é desfavorável a DA.

\section{REFERÊNCIAS}

APHA; AWWA; WEF. American Public Health Association; American Water Works Association; World Economic Forum. Standart methods for the examination of water and wastewater. $20 \mathrm{ed}$. Washington, 2005.

AHMAD, F.; SILVA, E. L.; VARESCHE, M. B. A.. Hydrothermal processing of biomass for anaerobic digestion: a review. Renewable and Sustainable Energy Reviews, v.98, p.108124, 2018. DOI: http://dx.doi:10.1016/j.rser.2018.09.008

ALBUQUeRQUE, L. S.; ARAÚJO, J. C. S.. Produção de biogás por co-digestão utilizando uma mistura de dejetos bovinos e casca de café conilon. Brazilian Journal of Production Engineering, São Mateus, v.2, n.3, p.44-54, 2016.

BINNER, R.; MENATH, V.; HUBER, H.; THOMM, M.; BISCHOF, F.; SCHMACK, D.; REUTER, M.. Comparative study of stability and half-life of enzymes and enzyme aggregates implemented in anaerobic biogas processes. Biomass Conversion and Biorefinery, v.1, n.1, p.1-8, 2011. DOI: http://dx.doi:10.1007/s13399-010-0002-y 
BRÉMOND, U.; BUYER, R.; STEYER, J. P.; BERNET, N.; CARRERE, H.. Biological pretreatments of biomass for improving biogas production: an overview from lab scale to full-scale. Renewable and Sustainable Energy Reviews, v.90, p.583-604, 2018. DOI:

http://dx.doi:10.1016/j.rser.2018.03.103

CAETANO, L.. Proposição de um sistema modificado para quantificação de biogás. Dissertação (Mestrado em Energia na Agricultura) - Universidade Estadual Paulista, Botucatu, 1985.

CHEN, J. L.; ORTIZ, R.; STEELE, T. W. J.; STUCKEY, D. C.. Toxicants inhibiting anaerobic digestion: a review. Biotechnology Advances, v.32, n.8, p.1523-1534, 2014. DOI: http://dx.doi:10.1016/j.biotechadv.2014.10.005

CHERNICHARO, C. A. L.. Reatores Anaeróbios. 2 ed. Princípios do Tratamento Biológico de Águas Residuárias. Belo Horizonte: UFMG, 2007.

CÓRDOVA, O.; SANTIS, J.; RUIZ-FILLIPI, G.; ZUÑIGA, M. E.; FERMOSO, F. G.; CHAMY, R.. Microalgae digestive pretreatment for increasing biogas production. Renewable and Sustainable Energy Reviews, v.82, p.2806-2813. DOI: https://doi.org/10.1016/i.rser.2017.10.005

COSTA, L. V.; MOGHRABI, J. A.; SAGULA, A. L.; JUNIOR, J. L.. Tratamento anaeróbico da água residuária de frigorífico com uso de biodigestores: utilização de remediadores biológicos para produção de biogás. Brazilian Journal of Biosystems Engineering, v.7, n.2, p.77-85, 2013.

FRANKE-WHITTLE, I. H.; WALTER, A.; EBNER, C.; INSAM, H.. Investigation into the effect of high concentrations of volatile fatty acids in anaerobic digestion on methanogenic communities. Waste Management, v.34, n.11, p.2080-2089, 2014. DOI: http://dx.doi:10.1016/j.wasman.2014.07.020

FERREIRA, L. R. A.; OTTO, R. B.; SILVA, F. P.; SOUZA, S. N. M.; SOUZA, S. S.; ANDO JUNIOR, O. H.. Review of the energy potential of the residual biomass for the distributed generation in Brazil. Renewable and Sustainable Energy Reviews, v.94, p.440-455, 2018. DOI:

http://dx.doi:10.1016/j.rser.2018.06.034

GARCIA, N. H.; BENEDETTI, M.; BOLZONELLA, D.. Effects of enzymes addition on biogas production from anaerobic digestion of agricultural biomasses. Waste and Biomass Valorization, v.10, p.3711-3722, 2019. DOI: http://dx.doi:10.1007/s12649-019-00698-7

GERHARDT, M.; PELENC, V.; BÄUML, M.. Application of hydrolytic enzymes in the agricultural biogas production: Results from practical applications in Germany.

Biotechnology Journal, v.2, n.12, p.1481-1484, 2007. DOI: http://dx.doi:10.1002/biot.200700220

IMENI, S. M.; PUY, N.; OVEJERO, J.; BUSQUETS, A. M.; BARTROLI, J.; PELAZ, L.;COLÓN, J.. Techno-economic assessment of anaerobic co-digestion of cattle manure and wheat straw (raw and pre-treated) at small to medium dairy cattle farms. Waste and Biomass Valorization, v.11, n.8, 2019. DOI: http://dx.doi:10.1007/s12649-019-00728-4

JAIN, S.; WOLF, I. T.; LEE, J.; TONG, Y. W.. Comprehensive review on operating parameters and different pretreatment methodologies for anaerobic digestion of municipal solid waste. Renewable and Sustainable Energy Reviews, v.52, p.142-154, 2015. DOI:

http://dx.doi:10.1016/j.rser.2015.07.091

KAUFMANN, T.. Sustainable livestock production: Low emission farm: The innovative combination of nutrient, emission and waste management with special emphasis on Chinese pig production. Animal Nutrition, v.3, p.104-112, 2015. DOI: http://dx.doi:10.1016/i.aninu.2015.08.001

KUNZ, A.; OLIVEIRA, P. A. V.. Aproveitamento de dejetos de animais para geração de biogás. Revista de Política Agrícola, v.14, n.3, 2006.

LIMA, D. M. F.; RODRIGUES, J. A. D.; BOE, K.; ALVARADOMORALES, M.; ELLEGAARD, L.; ANGELIDAKI, I.. Anaerobic modeling for improving synergy and robustness of a manure co-digestion process. Brazilian Journal of Chemical Engineering, v.33, n.4, p.871-883, 2016. DOI: http://dx.doi:10.1590/0104-6632.20160334s20150314

MAGDALENA, J.; BALLESTEROS, M.; GONZÁLEZ-FERNANDEZ, C.. Efficient anaerobic digestion of microalgae biomass: proteins as a key macromolecule. Molecules, v.23, n.5, p.1098, 2018. DOI: http://dx.doi:10.3390/molecules23051098

MERLINCHRISTY, P.; GOPINATH, L. R.; DIVYA, D.. A review on anaerobic decomposition and enhancement of biogas production through enzymes and microorganisms. Renewable and Sustainable Energy Reviews, v.34, p.167173, 2014. DOI: https://doi.org/10.1016/j.rser.2014.03.010

MøLLER, H. B.; SOMMER, S. G.; AHRING, B. K.. Methane productivity of manure, straw and solid fractions of manure. Biomass and Bioenergy, v.26, n.5, p.485-495, 2004. DOI: http://dx.doi:10.1016/i.biombioe.2003.08.008

NESHAT, S. A.; MOHAMMADI, M.; NAJAFPOUR, G. D.; LAHIJANI, P.. Anaerobic co-digestion of animal manures and lignocellulosic residues as a potent approach for sustainable biogas production. Renewable and Sustainable Energy Reviews, v.79, p.308-322, 2017. DOI: http://dx.doi:10.1016/j.rser.2017.05.137

ROCHA, D. T.; RESENDE, J. C.; MARTINS, P. C.. Evolução tecnológica da atividade leiteira no Brasil: Uma visão a partir do Sistema de Produção da Embrapa Gado de Leite. Juiz de Fora: Embrapa Gado de Leite, 2018.

ROMANO, R. T.; ZHANG, R.; TETER, S.; MCGARVEY, J. A.. The effect of enzyme addition on anaerobic digestion of Jose Tall Wheat Grass. Bioresource Technology, v.100, n.20, p.45644571, 2009. DOI:

http://dx.doi:10.1016/j.biortech.2008.12.065

PARAWIRA, W.. Enzyme research and applications in biotechnological intensification of biogas production. Critical Reviews in Biotechnology, v.32, n.2, p.172-186, 2012. DOI: http://dx.doi:10.3109/07388551.2011.595384

POLO, C. M.; DEL MAR CLEDERA-CASTRO, M.; MORATILLA SORIA, B. Y.. Reviewing the anaerobic digestion of food waste: from waste generation and anaerobic process to its perspectives. Applied Sciences, v.8, n.10, p.1804, 2018. DOI: http://dx.doi:10.3390/app8101804 
RODRIGUEZ, C.; ALASWAD, A.; BENYOUNIS, K. Y.; OLABI, A. G.. Pretreatment techniques used in biogas production from grass. Renewable and Sustainable Energy Reviews, v.68, p.1193-1204, 2017. DOI:

http://dx.doi:10.1016/j.rser.2016.02.022

SANTOS, T. M. B.. Balanço energético e adequação do uso de biodigestores em galpões de frangos de corte. Tese (Doutorado) - Faculdade de Ciências Agrárias e Veterinárias da UNESP, Jaboticabal, 2001.

SPEDA, J.; JOHANSSON, M. A.; ODNELL, A.; KARLSSON, M. Enhanced biomethane production rate and yield from lignocellulosic ensiled forage ley by in situ anaerobic digestion treatment with endogenous cellulolytic enzymes. Biotechnology for Biofuels, v.10, n.1, 2017. DOI: http://dx.doi:10.1186/s13068-017-0814-0
SILVEIRA FILHO, A. S. L.; MENSAH, J. H. R.; BATTISTON, K. M.; BARROS, M. S.; SANTOS, I. F. S.. Dimensionamento de um reator UASB para tratamento de efluentes domésticos e recuperação do biogás para produção energética: um estudo de caso em Pouso Alegre (MG). Revista Brasileira de Energias Renováveis, v.7, n.1, p.77-94, 2018. DOI: http://dx.doi.org/10.5380/rber.v7i1.57970

ZHANG, L.; LOH, K.-C.; ZHANG, J.. Enhanced biogas production from anaerobic digestion of solid organic wastes: Current status and prospects. Bioresource Technology Reports, v.5, p.280-296, 2018. DOI: http://dx.doi:10.1016/j.biteb.2018.07.005

ZULKIFLI, Z.; ISMAIL, S. B.; ZAHARI, M. S. M.; UMOR, N. A.; AZIZ, N. I. A.. Screening on biogas optimization of lignocellulose-based materials using enzymatic hydrolysis process. Chemical Engineering Transactions, v.45, p.15851590, 2015. DOI: http://dx.doi10.3303/CET1545265

A CBPC - Companhia Brasileira de Produção Científica (CNPJ: 11.221.422/0001-03) detém os direitos materiais desta publicação. Os direitos referem-se à publicação do trabalho em qualquer parte do mundo, incluindo os direitos às renovações, expansões e disseminações da contribuição, bem como outros direitos subsidiários. Todos os trabalhos publicados eletronicamente poderão posteriormente ser publicados em coletâneas impressas sob coordenação da Sustenere Publishing, da Companhia Brasileira de Produção Científica e seus parceiros autorizados. Os (as) autores (as) preservam os direitos autorais, mas não têm permissão para a publicação da contribuição em outro meio, impresso ou digital, em português ou em tradução. 